\title{
Exploring the Attitude of Managers towards Key Performance Indicators (KPIs) in Response to Public Sector Change: A Rasch Analysis
}

\author{
Nazirah Aziz, Wee Shu Hui, and Zamalia Mahmud
}

\begin{abstract}
In enhancing performance of civil services, the Government of Malaysia has taken extensive change initiatives to continuously reform the administration of public sector in Malaysia. The Government Transformation Programme (GTP) has been introduced in 2009 with the aim of improving overall performance of civil personnel and to improve delivery of services towards public at large. Among other change initiatives taken is the implementation of KPI to measure performance of civil personnel. The purpose of this study is to provide extensive review of past literatures regarding to financial management reforms in Malaysian public sector organization which bring to establishment of KPI. This study also aims to investigate the attitude of public sector managers towards KPIs in response to GTP. A total of 40 useable responses were collected from June to August 2012 using a web-based survey. Data was analyzed using Rasch measurement and Winsteps ${ }^{\circledR}$ 3.72.3. The study indicates that the public sector managers highly recognize the positive attitude towards KPIs as an important driver towards successful implementation of change.
\end{abstract}

Index Terms-Public sector change, key performance indicator (KPI), performance measurement system (PMS), Rasch measurement model.

\section{INTRODUCTION}

The public sector has long been subjected to criticism due to lack of accountability, inefficiency and poor performance [1], [2]. The public sector reform has started in the early 1980s and has always been seen and applied as a means to improve its administration capacity and performance. The aims of reforming the public sector are to provide effective and efficient, less expensive and better quality of services [3]. The recent reform has brought many changes in public sector management. As noted by [2], 'such reforms have not only transformed the structure of public bureaucracy or the way it operates, they have also radically altered the nature of the government and its role in the society' (pp. 339).

Much of the administrative reforms are known as New Public Management (NPM) [2]. Generally, the NPM is being implemented with the aim at improving the public sector efficiency and performance in the delivery of public services. There are several key features of NPM as highlighted by [2] The NPM emphasize more on decentralization of authority, downsizing, focusing on outcomes and results rather than

Manuscript received September 11, 2013; revised November 15, 2013.

Nazirah Aziz and Wee Shu Hui are with the Faculty of Accountancy, Universiti Teknologi MARA, Malaysia (email: nazirah_00@yahoo.com, weesh411@salam.uitm.edu.my).

Zamalia Mahmud is with the Centre for Statistical Studies, Faculty of Computer and Mathematical Science, Universiti Teknologi MARA, Malaysia (e-mail: zamalia@tmsk.uitm.edu.my). inputs and processes, adoption of private management style, and improving the management culture by emphasizing on the centrality of citizens. The NPM has brought changes in the process of budgeting, human resource management and quality initiatives that would enhance the efficiency of public bureaucracy [4].

This study viewed implementation of KPIs as one of the change initiative introduced by the government. This is consistent with prior researchers, such as [5] and [6] whereby the implementation of performance measures has been regarded as change effort to improve performance of an organization. Acknowledging the important role played by the management in change initiatives [5], [6], this study aims to examine the attitude of public sector managers towards KPIs in response to change efforts made by the government. It is important to note that the management received information from the policy makers, and then they are responsible for disseminating the information to the middle and lower management and staffs.

The remainder of this paper is organized as follows. Section II develops an understanding on the financial management reform in Malaysia. This section also provides a discussion on transforming Malaysia and past literature on the attitude of managers towards KPIs. Section III discusses the methodology employed for the study. Section IV reports analysis and results of the study. Finally, a summary of the findings and conclusion of the study are presented in Section V.

\section{LITERATURE REVIEW}

\section{A. Financial Management Reform in Malaysia}

The reform in Malaysian public sector took place in the early 1980s had resulted in transformation of role of the government from playing an active role in the economic development towards becoming a facilitator to the economic development. In an effort to reduce the government involvement in the economy and society, the privatization policy was chosen as a major strategy to help achieve the goals of national development [2].

Prior to the implementation of NPM, there are various tools and techniques used to measure performance of public agencies and public servants. Reference [1] addressed that performance of public agencies was measured by the use of performance planning and budgeting while individual performance was measured by the use of annual work objective.

The fundamental concept of NPM is the utilization of the practices of the private sector in the public sector 
organizations [7]. One of those practices is the use of a performance measurement system (PMS), which is associated with the use of key performance indicators (KPIs) [1]. The [8] reported that many government agencies had spent their time and money on the design and implementation of KPIs with the aim to improve their effectiveness and efficiency in the delivery of services to the public at large.

Continuing the effort made under the philosophy of NPM, the new administration embarked on instilling a performance based culture in civil servants [1]. As a result, a directive was issued in 2005 instructing all government agencies to implement the KPIs. The Economic Planning Unit [9] reported that almost all public agencies in Malaysia are required to implement the KPIs system by 2010.

Under the new KPIs system, performance of the Malaysian public sector is to be assessed in terms of:

- The efficiency and effectiveness of the process of service delivery,

- The human resource and financial productivity, and

- The customers' satisfaction toward the service received. (Source: [9], pp. 10)

Prior researcher pointed out that the aim of adopting the KPIs in public sector is to improve efficiency and effectiveness of government agencies in delivering the public services [7]. However, based on the example of KPIs provided in the circular, [1] argued that the 'emphasis of KPIs was more on output and activity measures rather than effectiveness and efficiency measures' (pp.76). Thus, this statement indicates that the policy maker need to improve on the design and implementation of performance measures, especially the KPI to ensure it can measure effectiveness and efficiency of public agencies and civil personnel.

\section{B. Transforming Malaysia}

The Prime Minister, Datuk Seri Mohd Najib in his Cabinet Appointment speech on 1 April 2009, he emphasizes "1 Malaysia: People First, Performance Now" as the new administrations tag line. This indicates that government is seriously focusing on improving performance towards achieving Vision 2020. In 2009, Performance Management and Delivery Unit (PEMANDU) was established to "oversee the implementation and assess progress of the Government Transformation Program (GTP) and Economic Transformation Program (ETP), facilitate as well as support delivery of both the National Key Result Areas (NKRAs), and National Key Economic Areas (NKEAs)" (http://www.pemandu.gov.my/). In addition, the role of PEMANDU was also to support the Unity and Performance Minister in implementing the Key Performance Indicators (KPIs) system. The aim of establishing GTP was to improve public services and helping the government to achieve the ideals of 1Malaysia, while the ETP was focusing more on sustainable initiative that will transform Malaysia into a high income nation by 2020 .

The introduction of transformation by the government affected the way managers performing their task. According to PEMANDU, each ministries need to set up the KPIs for each of their unit to achieve the NKRAs. Hence, managers need to perform their task in achieving KPIs for their unit or department.

\section{The Attitude of Managers towards KPIs}

Under the KPI system, performance of public agencies will be assessed every quarter. According to [1], an analysis of the (i) performance of each service delivery, (ii) reasons for the variances, and (iii) recommendations for corrective actions and improvement are to be undertaken. The Malaysian Administrative Modernisation and Management Planning Unit (MAMPU) is the agency responsible for administrative development and coordinating the implementation of KPIs. However, it has been reported that the KPI report is used only for internal purposes only [1]. As such, benchmarking of an agency performance relative to others was not required.

In another study done by [11] with the aim to look at the implementation of KPIs in response to Government Circular 20 , the authors found that the use of KPIs in government agencies has been successful in measuring organizational as well as individual performance. In addition, the use of KPIs also contributed to several improvements in their administration and service delivery towards public at large [11]. However, the authors noted in their research paper that their study was based on archival data, and thus it provides limited insight into how managers perceived relevance and usefulness of KPIs in measuring their performance (pp.103).

Prior researchers pointed out on the effectiveness of KPIs in measuring and improving performance of public agencies and individual performance in public sector [1]-[11].Based on the arguments provided in the previous studies [1], [7], [11], this study aims to explore the attitude of managers in the public sector towards the KPIs in response to change effort made the government through the implementation of GTP.

\section{Methodology}

This study employed a survey method to gather information from 40 managers working in various public sector organizations using convenience sampling. Managers were randomly selected from the database available on Prime Minister Office's website (www.pmo.org.my). Four ministries agreed to be involved in this study. There are Ministry of Housing and Local Government (MHLG), Ministry of Health (MOH), Ministry of Domestic Trade, Co-operatives and Consumerism (MDTCC), and Ministry of Tourism (MTour). Only senior managers (grade 48 and above) and hold position as Head of Department were chosen to be involved in this study as it is believed that the senior managers aware of performance measurement system of their department and this group of managers also responsible to disseminate information on change effort made the policy maker to their staffs.

Referring to Wright Map in Fig. 2, Managers with ID 1-8 are from MTour, managers with ID 9-15 are from $\mathrm{MOH}$, managers with ID 16-27 are from MDTCC, and managers with ID 28-40 are from MHLG.

Managers were assessed on their attitude towards KPIs where they need to respond to eight items based on a 5-point Likert scale ranging from (1) strongly disagree to (5) strongly agree. Data collection process was conducted between July and August 2012 using online digital questionnaire. The questionnaire was improvised based on feedback from the content experts and was subjected to reliability and validity 
analysis using selected Rasch measurement tools via the WINSTEPS $^{\circledR}$ 3.72.3 software.

The Rasch measurement is based on a probabilistic model which originates from the Linear Hierarchical Logistic Model [12]. In the Rasch philosophy, the data have to comply with the principles, or in other words, the data has to fit the model. From Rasch point of view, it is required to test whether the data allow for measurement on a linear interval scale specifically in a cumulative response process [13].

Based on the Rasch rating scale model, we will estimate $P_{n i l}$, the probability of person $\mathrm{n}$ choosing "disagree" (category 2 ) over "strongly disagree" (category 1) on any item $(i) . D_{i}$ is the difficulty of item $i$ and $F_{l}$ is the difficulty of the first threshold on item $(i)$. The rating scale model is illustrated in Eq. (1):

$$
P_{n i 1}\left(x=1 / B_{n}, D_{i}, F_{1}\right)=\frac{e^{\left(B-\left[D_{i}+F_{1}\right]\right)}}{1+e^{\left(B-\left[D_{i}+F_{1}\right]\right)}}
$$

\section{ANALYSIS AND RESULTS}

\section{A. Assessing Quality of the Data}

Table I presented the summary statistics of the data for this study. The important indicators to be observed in this table are including Cronbach Alpha, person reliability, person measure, valid responses, item reliability, and Model Error (ME). The data can be considered as to fit the model if all important indicators are in accepted range. Referring to Table I, a total of 318 data points arising from 40 respondents and 8 items was analyzed. The 318 responses recorded, was large enough to obtain a useful and stable person measure estimates and useful stable item calibrations. It yielded a Chi-Square value of 311.37 with 268 degree of freedom at $\mathrm{p}=0.0352$. The test of raw score Cronbach-Alpha $(\alpha)$ registered a reliability of 0.94 allowed further analysis of the instrument.

Table I also illustrates overall information about whether the data showed acceptable fit to the model. The mean infit and outfit for person and item mean squares are expected to be 1.0. As can be seen from Table I, the mean infit and outfit are 0.93 and 0.91 respectively; while the mean infit and outfit for items are 0.97 and 0.91 respectively. The mean standardized infit and outfit are expected to be 0.0 and here they are -0.6 for person and -0.1 for items. The standard deviation of the standardized infit is an index of overall misfit for persons and items. Using 2.0 as a cut-off criterion [12], both persons (standardized infit standard deviation $=1.73$ ) and items (standardized infit standard deviation $=0.29$ ) show an overall acceptable fit.

Separation is the index of spread of the person positions or items positions. Referring to [11], if item separation is 1.0 or below, the items may not have sufficient breadth in position. For persons, separation is 1.90 for the data at hand (real), and is 2.49 when the data has no misfit to the model (model). High separation index represent a large spread of items and persons along the continuum. The item separation index is 1.17 which is lower than for persons.

Separation determines reliability of items and persons [12].
Higher separation in concert with variance in person or item position yields higher reliability. The person separation reliability estimate for this data is 0.78 while the item separation reliability estimate is 0.58 . Low item reliability indicates that the sample is not big enough to precisely locate the items on the latent variable. Item reliability can increase with bigger sample size and produce stable item estimates. This estimate is expected to increase when more samples are gathered to produce a more reliable item estimate.

\section{B. Fit Statistic}

According to [16] a statistic known as 'fit' provides an internal mechanism for identifying inappropriate responses to the items, which allowing exclusion or re-assessment of persons whose response make no sense. For instance, our understanding of positive attitude towards KPIs as a construct should be reflected in the pattern of participants' responses. A person, who is ready for change, understands PM practices in their department and performing well in their managerial tasks would be expected to agree more strongly with items in survey (show positive attitude towards KPI) than someone who is less ready. In this case, the persons' understanding of the construct, his sincerity, and our own understanding of the construct should be examined [16]. Misfit person and item can be identified by three indicators: MNSQ, Z standard (ZSTD), and Point to Measure Correlation (PTMea Corr). The data are considered as misfit when it failed to fulfil the criteria indicated below:

- PtMea Corr is between 0.4 and 0.85

- Outfit MNSQ is between 0.6 and 1.4

- Outfit ZSTD is between -2 and +2

In a Rasch context, 'fit' statistics indicates how accurately or predictably data fit the model [17]. Fit statistics can be determined by infit and outfit, Mean-square (MNSQ) and Standardized Mean.

Overfit is indicated by a mean square value of less than 1.0, and negative standardized fit. Overfit is interpreted as too much variation in the response pattern, perhaps indicating the presence of redundant items. Underfit is indicated by a mean square greater than 1.6 and standardized fit of less than 2.0 suggests an unusual and/or inappropriate response pattern [12]. Table II shows that all items are within the range of acceptable fit which are 0.6 to 1.4. in addition, as can be seen in Fig. 1, all items are within the range of acceptable Standardized Mean which is $-2<\mathrm{ZSTD}<+2$.

\section{Unidimensionality}

Reference [14] defines unidimensional measurement as "all of the non-random variance found in the data can be accounted for by a single dimension of difficulty and ability" (p.24). Unidimensionality is crucial to assure the instrument is measuring the specific objective, in this case the attitude of managers towards KPIs. Rasch analysis applies the Principal Component Analysis (PCA) of the residuals; i.e how much variance is the instrument in measuring what is it supposedly to measure. 
TABLE I: SUMmary STATISTIC OF 8 MEASURED ITEMS

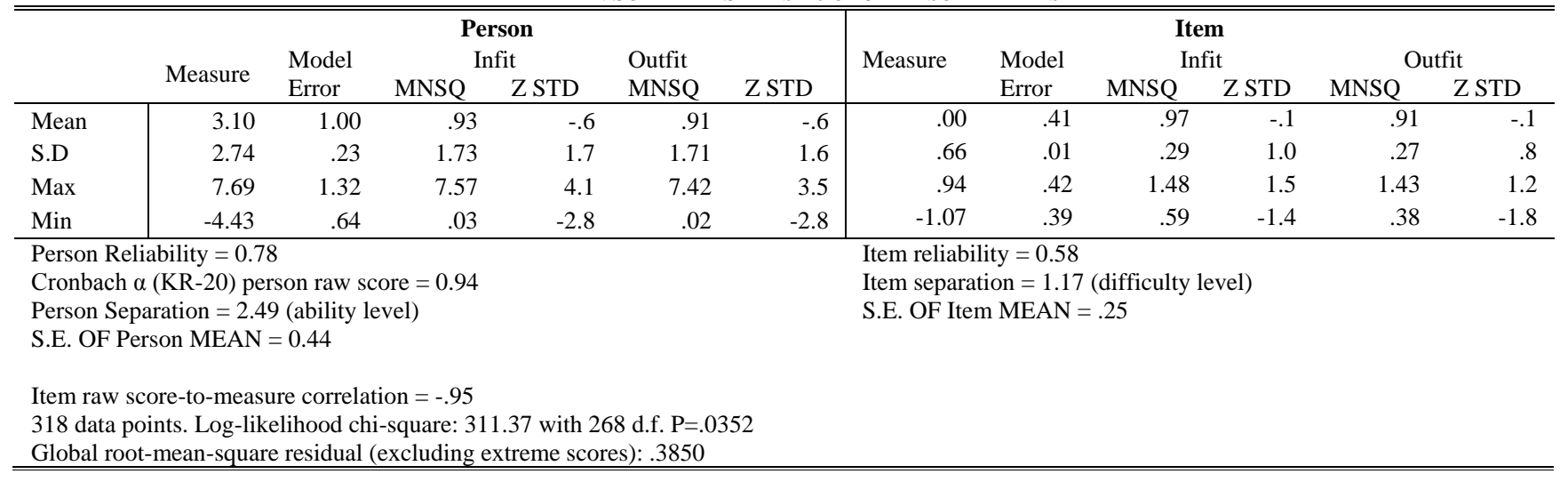

\begin{tabular}{|c|c|c|c|c|c|c|c|c|c|c|c|c|}
\hline \multirow{2}{*}{$\begin{array}{l}\text { Entry } \\
\text { number }\end{array}$} & \multirow{2}{*}{$\begin{array}{l}\text { Total } \\
\text { score }\end{array}$} & \multirow{2}{*}{$\begin{array}{l}\text { Total } \\
\text { count }\end{array}$} & \multirow{2}{*}{ Measure } & \multirow{2}{*}{$\begin{array}{l}\text { Model } \\
\text { S.E }\end{array}$} & \multicolumn{2}{|c|}{ Infit } & \multicolumn{2}{|c|}{ Outfit } & \multicolumn{2}{|c|}{ Pt-Mea } & \multirow{2}{*}{$\begin{array}{l}\text { Exact } \\
\text { OBS\% }\end{array}$} & \multirow{2}{*}{$\begin{array}{l}\text { Match } \\
\text { EXP\% }\end{array}$} \\
\hline & & & & & MNSQ & Zstd & MNSQ & Zstd & Corr. & Exp. & & \\
\hline 5 & 144 & 40 & .92 & .40 & 1.48 & 1.5 & 1.03 & .2 & A .76 & .81 & 77.5 & 81.6 \\
\hline 1 & 156 & 40 & -1.07 & .39 & 1.29 & 1.1 & 1.43 & 1.2 & В .65 & .75 & 82.5 & 78.7 \\
\hline 6 & 150 & 40 & -.09 & .41 & 1.21 & .7 & .93 & .0 & C. .78 & .79 & 77.5 & 82.0 \\
\hline 8 & 149 & 39 & -.44 & .42 & .82 & -.6 & .94 & .0 & D .76 & .78 & 84.6 & 81.3 \\
\hline 7 & 152 & 40 & .43 & .41 & .80 & -.6 & .93 & .0 & D .82 & .78 & 85.0 & 81.3 \\
\hline 2 & 151 & 40 & -.26 & .41 & .74 & -.9 & .87 & -.2 & C .83 & .79 & 87.5 & 81.8 \\
\hline 4 & 140 & 40 & .94 & .40 & .85 & -.4 & .80 & -.4 & В .84 & .81 & 79.5 & 81.4 \\
\hline 3 & 147 & 40 & .43 & .41 & .59 & -1.4 & .38 & -1.8 & A .88 & .81 & 90.0 & 82.5 \\
\hline Mean & 148.6 & 39.8 & .00 & .41 & .97 & -.1 & .91 & -.1 & & & 83.0 & 81.3 \\
\hline S.D & 4.6 & .4 & .66 & .01 & .29 & 1.0 & .27 & .8 & & & 4.3 & 1.1 \\
\hline
\end{tabular}

TABLE III: STANDARDIZED RESIDUAL VARIANCE

\begin{tabular}{|c|c|c|c|c|c|}
\hline & & \multicolumn{2}{|c|}{ Empirical } & \multicolumn{2}{|r|}{ Modeled } \\
\hline Total raw variance in observations & $=$ & 24.0 & $100 \%$ & & $100 \%$ \\
\hline Raw variance explained by measures & $=$ & 16.0 & $66.6 \%$ & & $65.9 \%$ \\
\hline Raw variance explained by persons & $=$ & 13.3 & $55.3 \%$ & & $54.7 \%$ \\
\hline Raw variance explained by items & $=$ & 2.7 & $11.3 \%$ & & $11.2 \%$ \\
\hline Raw unexplained variance (in total) & $=$ & 8.0 & $33.4 \%$ & $100 \%$ & $34.1 \%$ \\
\hline Unexplained variance in $1^{\text {st }}$ contrast & $=$ & 3.1 & $13.0 \%$ & $39 \%$ & \\
\hline
\end{tabular}

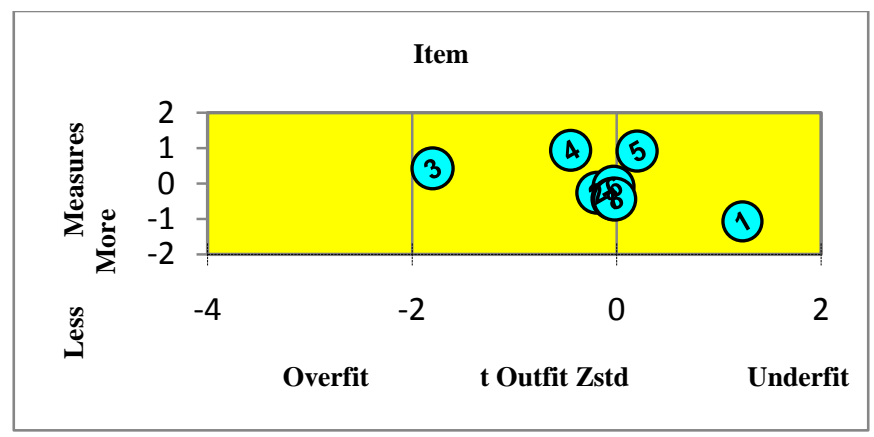

Fig. 1. Bubble chart (pathway)

The raw variance explained by measures is $66.6 \%$ closely match to the expected $65.9 \%$. Thus it meets unidimensionality requirement minimum which is $40 \%$ [15]. Nevertheless, the unexplained variance in the $1^{\text {st }}$ contrast of $3.1 \%$ as tabulated in Table III indicates that the instrument used in this study considered as good [18].

\section{Wright Map}

The heart of Rasch analysis is provided in Fig. 2, which is the Wright Map (also known as Person Item Distribution Map). Items and persons (or respondents) share the same linear measurement units known as logits. Referring to [13], logits is a unit derived from transforming ordinal data into an interval scale.

The Wright Map illustrates all and more importantly the hierarchy of difficulty order. This will be the premise of the construct validity acceptance [12]. Persons are distributed on the left side of the logit ruler and items are distributed on the right side. Those at the upper end of the scale agreed with more items and agreed more strongly. Letter "M" denotes the managers' item mean, " $\mathrm{S}$ " is one standard deviation away from the mean and "T" marks two standard deviations away from the mean.

As can be seen in Fig. 2, 40 managers are mapped on the left side of the map under the heading 'persons'. The distribution of respondents' positions is on the left side of the vertical dashed line in increasing order of ability. Those at the upper end of the scale agreed with more items and agreed strongly. Managers with ID number 19, 26 and 25 are found to have agreed completely with all the items, followed closely by managers with ID number 28,30 and 4 . About $47.5 \%$ (19/40) managers agreed with all items in measuring the attitude towards KPIs (ID number 40, 11, 13,..08).

In the map, we can see that $77.5 \%$ (31/40) managers fall above of all 8 items. These group of managers considered that the KPI of their department to be valid, and also agreed that 
the KPI in their department are being measured extensively (refer to item I_4 and item I_5).

Fig. 2 reported that the attitude of managers with ID number 12, 14 and 37 matches item I_3. This indicates that these three managers neither agree nor disagree that the KPIs of their department can be considered as reliable (refer to item I_3). They also have a neutral agreement that they involve in developing a better KPIs for their department (refer to item I_6).

Fig. 2 also reported that the managers with ID 15, 29 and 9 matches the items I_1. This indicates that these groups of managers are having a neutral agreement with their familiarity with the KPIs of their department.

There is also an indication of redundancy among the items as shown on the map. These items are labeled as I_2, I_7 and
I_8. I_2 is measuring whether the managers agreed that the KPI in their department are easy to understand. I_7 is measuring whether the managers consider the present departmental KPI are useful for their department, while I_8 is measuring whether the managers consider the present departmental KPI are useful for them "personally".

This study indicates that there are 2 managers shows disagreement with almost all items in the survey, which are managers with ID 10 and 17 . In order to gauge possible reasons to explain this issue, the researcher had email both managers. According to these two managers, they are not the Head of Department in their organizations, and they are not aware of their KPIs. Thus, this indicates that these two managers did not received information from the superior regarding to the issue of performance measures.

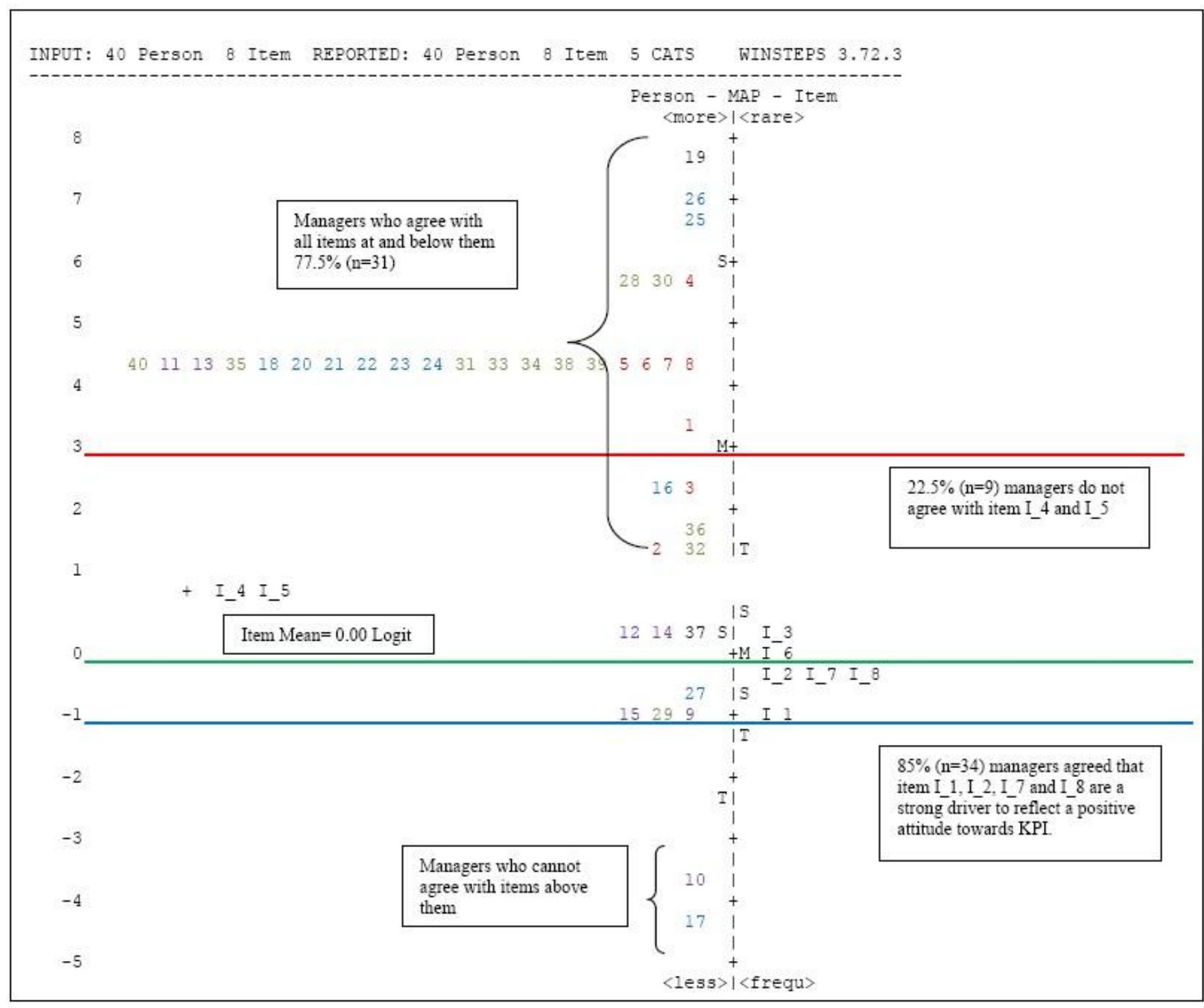

Fig. 2. Wright map

\section{DiscusSIONS AND CONCLUSION}

The Government of Malaysia has faced continual administrative reforms to enhance its efficiency and effectiveness in delivering the public services. The financial management reform has started along with the New Public Management back in 1980s. However, prior literatures, the media and the Auditor General office reported unsatisfactory performance among public agencies and public servants. The Prime Minister addressed the importance of improving performance of public sector organizations through implementation of Key Performance Indicators (KPIs). The purpose of this study is to assess the attitude of public sector managers towards performance measures, specifically the KPIs of their organizations. Results indicate that the senior managers are aware and show positive attitude towards KPIs 
in their department. However, this study found that the middle and lower management did not receive enough information and clear direction on the issue of performance measures of their department. Thus, it is important for the senior management to disseminate all necessary information received by the policy maker to the middle and lower management to ensure successful implementation of performance measures in public sector organizations.

\section{ACKNOWLEDGMENT}

We would like to thank Accounting Research Institute, Universiti Teknologi MARA and Ministry of Higher Education Malaysia for the financial and research funding support through Fundamental Research Grant Scheme (FRGS).

\section{REFERENCES}

[1] A. K. S. Nabiha, "New Public Management in Malaysia: In search of an efficient and effective service delivery," International Journal of Management Studies, vol. 15, pp. 69-90, 2008.

[2] N. A. Siddique, "Public management reform in Malaysia. Recent initiatives and experiences," International Journal of Public Sector Management, vol. 19, no. 4, pp. 339-358, 2006

[3] W. Webb, "Public management reform and the management of ethics: Incompatible ideals for the developing state?" International Journal of Public Sector Management, vol. 23, no. 7, pp. 669-684, 2010.

[4] R. Common, Public Management and Policy Transfer in Southeast Asia, Ashgate, Aldershot, 2005.

[5] D. Boukenooghe, G. Devos, and H. V. D. Broeck, "Organizational change questionnaire- climate of change, processes, and readiness: Development of a new instrument," The Journal of Psychology, vol 143, no. 6, pp. 559-599, 2009.

[6] I. Cinite, L. E. Duxbury, and C. Higgins, "Measurement of perceived organisational readiness for change in the public sector," British Journal of Mangement, vol. 20, pp. 26- 277, 2009.

[7] C. Hood, "The new public management in the 1980's: Variations on a theme," Accounting, Organization, and Society, vol. 20, no. 2, issue 3, pp. 93-109, 1995.

[8] OECD, Performance Auditing and Modernisation of Government, Paris: OECD Press, 1996.

[9] Economic Planning Unit (EPU). [Online]. Available: http://www.epu.gov.my

[10] DAC Development Administration Circular No. 2 of 2005, Guideline on establishing key performance indicators (KPI) and implementing performance assessment at government agency.

[11] Z. Zakaria, M. A. Yaacob, Z. Yaacob, N. Noordin, M. Z. H. Mohamed Sawal, and Z. Zakaria, "Key Performance Indicators (KPIs) in the Public Sector: A study in Malaysia," Asian Social Science, vol. 7, no. 7, pp. 102-107, 2011

[12] Z. Mahmud, "Diagnosis of perceived attitude, importance, and knowledge in statistics based on Rasch probabilistic model," International Journal of Applied Mathematics and Informatics, vol. 5, pp. 291-298, 2011.

[13] M. S. Masodi, "Instrument construct validation of VFMA 35 for the conduct of Value for Money Audit using Rasch Model," Integrated Advanced Planning Sdn Bhd, Kuala Lumpur, Malaysia, 2008.
[14] J. Sick, "Rasch measurement in language education Part 5: Assumptions and requirements of Rasch measurement," SHIKEN: JAKT Testing and Evaluation SIG Newsletter, vol. 14, no. 2, pp. 23-29, 2010

[15] K. J. Conrad, K. M. Conrad, M. L. Dennis, B. B. Riley, and R. Funk, "Validation of the Substance Problem Scale (SPS) to the Rasch Measurement Model, GAIN Methods," Report 1. 2. 2011

[16] K. E. Green and C. G. Frantom. "Survey development and validation with the Rasch model," A paper presented at the International Conference on Questionnaire Development, Evaluation, and Testing, Charleston, SC, November 14-17, 2002.

[17] J. M. Linacre, "Optimizing Rating Scale Category Effectiveness," Journal of Applied Measurement, vol. 3, no. 1, pp. 85-106, 2002.

[18] W. P. J. Fisher, "Rating scale instrument quality criteria," Rasch Measurement Transactions, vol. 21, no. 1095, 2007.

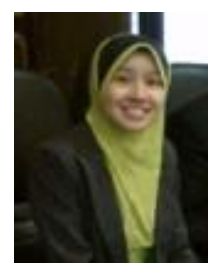

Nazirah is currently a PhD student of the Faculty of Accountancy, Universiti Teknologi MARA, Malaysia. Her research interests include Management Accounting Change and Performance Measurement System with specific attention to readiness towards public sector change. She was working as an Accounting Lecturer at Management and Science University for almost one year before being offered by Ministry of Education of Malaysia and UiTM to further her PhD under Young Lecturer Scheme's scholarship. She has attended more than 5 national and international conferences in the past three years and one of her paper is currently under review to be published by an indexed international journal. She is currently at the stage of completing her write-up.

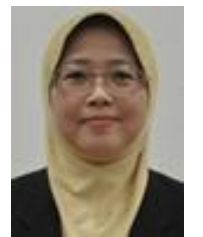

Zamalia Mahmud is currently a teaching staff of the Faculty of Mathematical and Computer Science, University Teknologi MARA, Malaysia. She has been an academician for over 20 years and her main area of research interest covers Statistical Education Reserch, Statistical Methods and Inferences,Data Analysis and Interpretation Using SPSS and Rasch Measurement Model. She has led numerous research and consultancy project organised by UiTM and other government agencies. She has more than 10 publications for the past 10 years. She is an evaluator for UiTM PhD Students' Defence of Research Proposal also a reviewer for IRDC/FRGS and Dana Kecemerlangan Research. She has participated in Invention, Innovation and Design (IID) Exhibition for more than three times and has been awarded as the best presenter in Insights 2002 Conference, PWTC, August 2002.

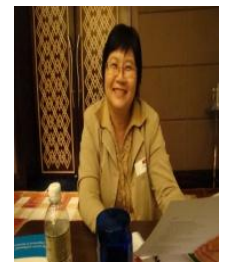

Wee Shu Hui is currently a Research Fellow with the Accounting Research Institute, and is also a teaching staff of the Faculty of Accountancy, University Teknologi MARA, Malaysia. She has been an academician for over 20 years and her main area of research interests covers management accounting, strategic performance measurement systems and cost. She enjoys researching, is an active researcher, has led numerous research and consultancy projects and is currently spearheading an international research project. She has written several books on management accounting and published her research findings in refereed and indexed journals. Shu Hui is Asia-Pacific Management Accounting Journal (APMAJ) administrator, and is the secretary of Asia-Pacific Management Accounting Association (APMAA). Also, she is an assessor with the National Award for Management Accounting (NAfMA) 